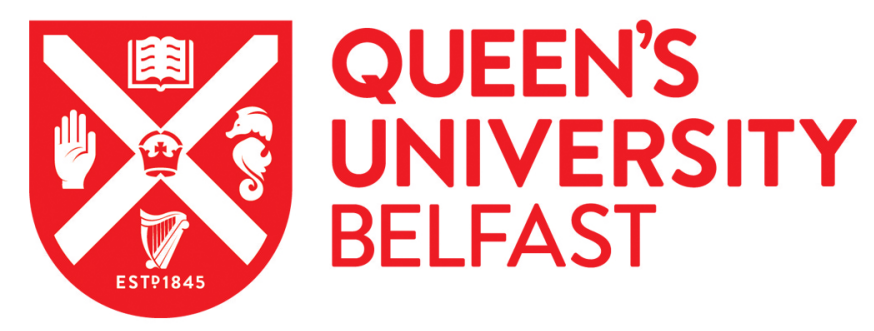

\title{
Psychotropic prescribing patterns among adolescents in Northern Ireland presenting with psychotic symptoms during a 5-year period
}

Woods, G., Shannon, C., Davidson, G., Hoy, K., Lewis, D., Tumelty, L., \& Mulholland, C. (2016). Psychotropic prescribing patterns among adolescents in Northern Ireland presenting with psychotic symptoms during a 5-year period. Irish Journal of Psychological Medicine, 33(1), 13-20. https://doi.org/10.1017/ipm.2015.12

\section{Published in:}

Irish Journal of Psychological Medicine

\section{Document Version:}

Peer reviewed version

Queen's University Belfast - Research Portal:

Link to publication record in Queen's University Belfast Research Portal

Publisher rights

(c) College of Psychiatrists of Ireland 2015

\section{General rights}

Copyright for the publications made accessible via the Queen's University Belfast Research Portal is retained by the author(s) and / or other copyright owners and it is a condition of accessing these publications that users recognise and abide by the legal requirements associated with these rights.

Take down policy

The Research Portal is Queen's institutional repository that provides access to Queen's research output. Every effort has been made to ensure that content in the Research Portal does not infringe any person's rights, or applicable UK laws. If you discover content in the Research Portal that you believe breaches copyright or violates any law, please contact openaccess@qub.ac.uk. 


\section{Psychotropic prescribing patterns among adolescents in Northern Ireland presenting with psychotic symptoms during a five-year period}

\section{Abstract}

Objective: to report new prescriptions of psychotropic medications among adolescents presenting with new onset psychotic symptoms during a five-year period.

Methods: The Northern Ireland Early Onset Psychosis Study (NIEOPS) is a naturalistic longitudinal observational study of patients with an early onset first psychotic episode. All patients aged less than 18 years presenting to specialist mental health services across Northern Ireland with new onset psychotic symptoms between 2001 and 2006 were recruited $(n=113)$. Clinical case notes were analysed retrospectively for details of subsequent treatment with psychotropic medications. Results: A total of 100 patients (88.5\%) were prescribed some form of psychotropic medication. Over three-quarters of patients received an antipsychotic as their first medication. Risperidone (45.8\%), olanzapine (24.0\%) and chlorpromazine (12.5\%) were the most commonly prescribed first-line antipsychotic medications. Of a total of 160 antipsychotic prescriptions, $81(50.6 \%)$ were off-label. Prescriptions were most likely to have been deemed off-label due to medications not being licensed in under-18s (71.6\% of off-label prescriptions) but other reasons were medications being used outside licensed age ranges (23.5\%) and outside licensed indications (4.9\%).

Conclusions: This is the first study examining psychotropic prescribing patterns in a complete sample of all children and adolescents presenting with early onset psychotic episodes in a single geographical area. The observation of risperidone as the most commonly-prescribed antipsychotic was in keeping with previous studies in child and adolescent populations. Rates of off-label prescribing were lower than previously observed although our study was the first to investigate offlabel prescribing solely in children and adolescents presenting with psychotic symptoms. 


\section{Keywords}

Psychosis, children, adolescents, antipsychotics, psychotropics, off-label 


\section{Introduction}

Although antipsychotics are being used with increasing frequency in child and adolescent populations, it is acknowledged that little is known about the characteristics of those prescribed them (Olfson et al., 2006). Previous analyses of antipsychotic use in this age group have almost invariably included young persons being prescribed antipsychotics for a myriad of indications. We are only aware of one previous study looking at psychotropic prescribing patterns specifically in a child and adolescent first-episode psychosis population (Castro-Fornieles et al., 2008).

The Northern Ireland Early Onset Psychosis Study is the first to investigate psychotic disorders in children and adolescents in this region of the United Kingdom (UK), mirroring the extensive body of work among the region's adults in the Northern Ireland First Episode Psychosis Study (NIFEPS) (Barrett et al., 2009; Turkington et al., 2009). Northern Ireland's total population in 2001 was $1,685,267$, of whom $451,514(27.0 \%)$ were aged less than 18 years. The total UK population in 2001 was $58,789,194$. Northern Ireland has a higher proportion of young people under the age of 16 (24\%) than the UK average (20\%). Specialist, or secondary care, child and adolescent mental health services (CAMHS) are provided throughout Northern Ireland across several sites and comprise both community and hospital facilities. Within the UK, secondary care services are provided by medical specialists who generally do not have first contact with patients, who have typically been referred to secondary care by their primary care provider (General Practitioner).

Antipsychotic prescriptions in children and adolescents in the UK almost doubled between 1993 and 2005 (Rani et al., 2008). This was driven by a large increase in the prescription of secondgeneration antipsychotics, whereas the prescription of first-generation antipsychotics began to fall during the latter five years of this time period. The increase in antipsychotic prescribing among children and adolescents is even more dramatic in the United States (US) where two to six-fold 
increases have been observed during similar time periods, with similar trends to those in the UK noted in the use of first- and second-generation preparations (Cooper et al., 2004; Aparasu et al., 2005; Cooper et al., 2006; Olfson et al., 2006).

The changing pattern of antipsychotic prescribing among children and adolescents has mainly been attributed to the less severe adverse effect profiles of the second-generation preparations, thereby allowing their use in situations where historically the first-generations' risk-benefit ratio was not considered to favour the use of an antipsychotic (Olfson et al., 2006). Although the secondgeneration antipsychotics have a lesser propensity for extra-pyramidal side effects they are associated with metabolic disturbance and weight gain, to which adolescents may be more vulnerable than their adult counterparts (Stigler et al., 2004; Pogge et al., 2005). Other factors suggested to have been involved in increasing antipsychotic prescribing are the expanding evidence base in relation to antipsychotic use in this age group (Harrison et al., 2012) and a lack of availability of non-pharmacological treatments (Thomas et al., 2006).

It is noted that a growing number of antipsychotic prescriptions among children and adolescents are for 'off-label' use in the treatment of non-psychotic conditions such as conduct and behavioural disorders (Otasowie et al., 2010). Although accepted as commonplace in the general adult setting, the extent of off-label prescribing among children and adolescents in the UK is unknown (Baldwin and Kosky, 2007). At the time of our study there were few antipsychotics licensed for use in the under $18 \mathrm{~s}$, even in the presence of a diagnosed psychotic illness. The first-generation antipsychotics chlorpromazine and haloperidol were licensed for use in psychoses from very young ages and the second-generation antipsychotics amisulpride, sulpiride, clozapine and risperidone licensed for use in the mid-to-late teens. Olanzapine, quetiapine and the depot antipsychotic preparations were not licensed for use below the age of 18 . 
The NIEOPS is a multicentre naturalistic observational study designed to assess the clinical characteristics and interventions, both pharmacological and non-pharmacological, observed in children and adolescents presenting to specialist services with new onset psychotic symptoms in Northern Ireland. Psychotropic prescribing patterns and rates of off-label use of medication were studied, with particular interest afforded to antipsychotic prescriptions. The study was agreed and funded by the Northern Ireland Regional Multiprofessional Audit Group and the use of data collected as part of patients' care was formally approved by all health care organisations involved for use in the study.

\section{Method}

At the time of conducting the study, Northern Ireland did not possess a case register for new onset psychotic episodes and we relied on clinician recall and cooperation for recruitment of potential subjects. CAMHS clinicians were appraised of the study in advance and requested to forward details of any person under the age of 18 years presenting to secondary care services with new onset psychotic symptoms such as delusions or hallucinations. All of the region's consultants in general adult psychiatry were also contacted and requested to consider reporting eligible patients who had presented directly to adult services.

Exclusion criteria were moderate intellectual disability (IQ $<50$ ) or gross neurological disorder. Substance misuse was not an exclusion criterion. It is noted that psychotic symptoms have been observed to be common in childhood and not necessarily indicative of a psychotic illness. Such symptoms do not therefore prompt a referral to secondary care in all cases and as such we excluded all cases that were being monitored or managed in the primary care setting.

A record was subsequently kept of children and adolescents presenting to secondary care mental 
health services with new onset psychotic symptoms in Northern Ireland between 01 July 2001 and 30 June 2006. Presentations were either to outpatient services or in several cases via direct hospital admission. Clinical case notes were subsequently analysed and information recorded for demographic variables, hospital admissions, involuntary admissions and both pharmacological and non-pharmacological interventions. Medications were classed as psychotropics if they were being used to treat a psychiatric condition or to ameliorate the side-effects of a psychotropic medication (such as antipsychotic-induced extrapyramidal side effects). Antiepileptics being used solely for the management of epilepsy were excluded from the study.

The first new medication prescribed after presentation was accorded particular significance and its drug class recorded. Only regularly prescribed medications were recorded in this group and shortterm prescriptions or 'as required' medications excluded. If a medication was already being prescribed prior to assessment and it was deemed appropriate to continue this, this preparation was recorded as the first new medication.

The first new antipsychotic, antidepressant, antiepileptic, benzodiazepine and 'other' medication (including mainly hypnotics and procyclidine, but also lithium) prescribed were recorded where applicable. Second and third line agents were recorded for the antipsychotic, antidepressant and other categories, and fourth line agents recorded for antipsychotics.

In each case where psychotropic medication was prescribed, the British National Formulary (BNF) for children 2007 (Paediatric Formulary Committee, 2007)was used to determine whether or not this use was off-label. Medications were determined to have been prescribed off-label if they had been prescribed outside licensed indications, or outside the licensed age, dose or treatment duration ranges. 


\section{Statistical analysis}

Data were analysed using SPSS version 19.0 (IBM Corp., 2010). The Chi-square test was used to compare the frequency of both antipsychotic and antidepressant prescribing by gender.

\section{Results}

\section{Patient characteristics}

A total of 113 subjects were identified during the five-year period. Mean age at first presentation with psychotic symptoms was $15.1 \pm 1.7$ years (range $10-17) .72$ persons $(63.7 \%)$ were male and 41 (36.3\%) female. 111 of $113(98.2 \%)$ of patients were of Caucasian ethnicity. 26 of $113(23.0 \%)$ patients had previously been in contact with mental health services. 83 of $113(73.5 \%)$ patients were admitted to hospital at some point during the study period. Of those admitted to hospital, 36 (43.4\%) were involved in compulsory or detained admissions under the Mental Health (Northern Ireland) Order 1986. Diagnoses were unavailable for the full dataset and are not included in the study results.

Non-pharmacological interventions

A total of 67 patients (59.3\%) received a psychological therapy treatment. In all, 36 patients (31.9\%) received family work, $43(38.1 \%)$ an educational intervention and $29(25.7 \%)$ an occupational therapy intervention.

Psychotropic medication prescribing 
A total of 100 participants $(88.5 \%)$ were prescribed some form of psychotropic medication (see

Table 1). Retrospective analysis of the entire clinical case notes was not possible for all of the 113 subjects as five volumes of notes were lost during a fire at one inpatient site.

Of those patients prescribed psychotropic medication, $65 \%$ received an antipsychotic in isolation as the first type of medication prescribed, $14 \%$ received an antidepressant, $13 \%$ of patients were simultaneously commenced on both an antipsychotic and an antidepressant and $4 \%$ received a benzodiazepine as their first regularly prescribed medication (see Table 2). One patient received a stimulant medication as their first psychotropic.

\section{Antipsychotic prescribing}

In all, 96 patients $(85.0 \%)$ were prescribed an antipsychotic at some point of the study (see Table 3 ). Of the first-line antipsychotics, risperidone (45.8\%) was the most frequently prescribed, followed by olanzapine $(24.0 \%)$ and chlorpromazine $(12.5 \%)$. Risperidone $(20.5 \%)$ was also the most commonly prescribed second-line antipsychotic, again followed by olanzapine and chlorpromazine (both 15.9\%). Olanzapine and clozapine (both 20.0\%) were the most commonly prescribed thirdline antipsychotics, followed by aripiprazole (15.0\%), amisulpride and haloperidol (both 10.0\%). Risperidone (33.3\%) was the most commonly prescribed of the fourth-line antipsychotics, followed by chlorpromazine $(22.2 \%)$. Two of the three risperidone prescriptions at this stage were for the medication's intramuscular depot preparation. With the exception of cross-titration periods, there were no instances of more than one antipsychotic being prescribed simultaneously.

\section{Antidepressant prescribing}

A total of 43 patients (38.1\%) were prescribed an antidepressant during the study period (see Table 
4). Fluoxetine (48.8\%) was the most frequently prescribed of the first-line antidepressants, followed by sertraline $(23.3 \%)$, mirtazapine and citalopram (both $9.3 \%)$. Sertraline $(46.2 \%)$ was the most frequently prescribed second-line antidepressant, followed by fluoxetine and mirtazapine (both 15.4\%) and clomipramine, dosulepin and venlafaxine (all 7.7\%). Venlafaxine (33.3\%) was the most commonly prescribed third-line antidepressant, followed by dosulepin, lofepramine, mirtazapine and sertraline (all 16.7\%).

Prescribing of other psychotropic medications

Sodium valproate $(70.8 \%)$ was the most commonly prescribed first-line antiepileptic.

Carbamazepine (12.5\%), lamotrigine (12.5\%) and gabapentin (4.2\%) were prescribed with lesser frequencies.

Diazepam (52.4\%) accounted for more than half of first-line benzodiazepine prescriptions, lorazepam (38.1\%) and temazepam (9.5\%) making up the remainder.

There was a wide range of first 'other' medications prescribed, half of which were accounted for by lithium and procyclidine (see Table 5).

Off-label psychotropic medication prescribing

Rates of off-label prescribing among the antipsychotic medications remained largely stable at around $55 \%$ as patients moved from first to fourth-line agents (see Table 6).

Antidepressant prescribing was entirely off-label, as was the use of benzodiazepines and antiepileptics. Almost two-thirds (65.4\%) of the first 'other' medications were off-label prescriptions. 
We looked in particular at reasons for the antipsychotic prescriptions being deemed to be off-label, categorising them as such for one of four main reasons: (i) not licensed at all in under-18s; (ii) prescribed outside licensed age range; (iii) prescribed outside licensed indication(s); (iv) prescribed outside licensed dose range (Table 7).

Of the 81 off-label prescriptions, $58(71.6 \%)$ were for preparations not licensed at all in under-18s, the majority of such prescriptions being accounted for by olanzapine and quetiapine. A further 19 (23.5\%) prescriptions were for medications being used outside (more specifically below) the licensed age range. Four (4.9\%) prescriptions were for medications being used outside their licensed indications (see Table 7).

\section{Psychotropic prescribing by gender}

We tested for an association between gender and the prescription of either antipsychotics or antidepressants. Although antipsychotics were prescribed more frequently among males $(83.3 \%$ of males and $68.3 \%$ of females $)$ and antidepressants more frequently among females $(31.9 \%$ of males and $48.8 \%$ of females), a Chi-square test for independence (with Yates Continuity Correction) indicated no significant association between gender and the prescription of either antipsychotics, $\chi^{2}$ $(1, \mathrm{n}=113)=2.6, \mathrm{p}=.11$, phi $=-.17$ or antidepressants $\chi^{2}(1, \mathrm{n}=113)=2.5$, $\mathrm{p}=.12, \mathrm{phi}=.17$.

\section{Discussion}


As the first study to examine psychotropic prescribing patterns in a complete sample of children and adolescents presenting with early onset psychotic episodes in a single geographical area, our paper provides an invaluable overview of characteristic treatments, particularly psychotropic prescribing patterns, in this population during a recent five-year time period. The age profile of our study group was almost identical to that observed in a similar study of 110 adolescents with early onset psychosis by the CAFEPS group in Spain(Castro-Fornieles et al., 2008). The 2:1 male to female ratio we observed had previously been seen in a study of children and adolescents presenting to outpatients and being prescribed antipsychotics in a large cross-sectional analysis in the US (Aparasu and Bhatara, 2007). It has been demonstrated elsewhere that adolescent males are more than twice as likely to be prescribed antipsychotics as their female counterparts (Olfson et al., 2006). Such patterns are in keeping with the earlier average age of onset of schizophrenia in males (15-25 years) than females (25-35 years) (Hafner et al., 1994).

Our observation that over three-quarters of persons were prescribed an antipsychotic as their first new medication (either alone or in combination with an antidepressant) was understandable given that all of our study participants were referred due to new onset psychotic symptoms. The high rates of hospital admissions and detentions under the Mental Health (Northern Ireland) Order 1986 were reflective of the high levels of morbidity among our study population.

Risperidone has repeatedly been demonstrated to be the most commonly prescribed antipsychotic among child and adolescent populations (Pappadopulos et al., 2002; Doerry and Kent, 2003; Sivaprasad et al., 2006; Aparasu and Bhatara, 2007; Castro-Fornieles et al., 2008; Haw and Stubbs, 2010) and our finding of risperidone as the most commonly prescribed of both the first- and secondline antipsychotics was consistent with such studies. The frequency of risperidone prescribing would appear to be attributable to the fact that it was the only one of the more commonly used 
second-generation antipsychotics to be licensed in the under-18s (possessing a licence for use between 15-18 years), with both olanzapine and quetiapine not licensed at all among this age group. The three most commonly prescribed first-line antipsychotics observed in our study accounted for over $80 \%$ of prescriptions and were risperidone $(45.8 \%)$, olanzapine $(24.0 \%)$ and chlorpromazine (12.5\%). Three antipsychotic medications accounted for more than three-quarters of antipsychotic prescriptions in the CAFEPS group's baseline findings, with risperidone (45.5\% of patients), quetiapine (16.4\%) and olanzapine (14.5\%) predominating (Castro-Fornieles et al., 2008). The CAFEPS study was conducted during the two year period 2003-2005 which fell within the time limits of our study.

First-generation antipsychotics accounted for $14.6 \%$ of first-line antipsychotic prescriptions in our study, a higher proportion than we had envisaged. Of the 14 prescriptions for first-generation antipsychotics, $12(85.7 \%)$ were for chlorpromazine. Haloperidol was the only first-generation antipsychotic prescribed at baseline in the CAFEPS group, where it was used in only $1.8 \%$ of persons(Castro-Fornieles et al., 2008). A cross-sectional analysis of outpatient child and adolescent antipsychotic prescriptions in the US showed rates of first-generation antipsychotic prescribing of only 1.0\% (Aparasu and Bhatara, 2007), although an earlier analysis between 2000-2002 demonstrated a rate of $7.7 \%$ (Olfson et al., 2006). We considered whether the chlorpromazine use in our study was clustered in one particular centre and reflective of individual rather than collective practice but were unable to determine this retrospectively from analysis of the anonymised data. Other possible explanations for the preponderance of chlorpromazine prescribing may have included the fact that it is licensed for use even in very young children (from 1 year) and the long period of clinician experience and familiarity of use that is associated with long-established preparations, with both factors likely to reduce prescriber anxiety regarding its use.

We were surprised to see zuclopenthixol, as a relatively uncommonly used first-generation 
antipsychotic, among the first-line antipsychotic medications. It is however important to consider that we studied medication prescriptions after presentation with new onset psychotic symptoms, rather than first exposure to any antipsychotic medication. A large proportion $(23.0 \%)$ of persons in our study had had prior contact with mental health services and may have previously been exposed to one or more antipsychotics for the treatment of non-psychotic conditions. It is also feasible that subjects may have previously had antipsychotics prescribed at primary care level. We believe that it is therefore unlikely that this prescription was that person's first exposure to antipsychotic medication.

The increasing use of clozapine and antipsychotic long-acting injections with each successive change of medication was similar to patterns expected among adult populations and is reflective of treatment resistance and concerns regarding medication non-compliance.

The predominance of the selective serotonin reuptake inhibitors (SSRIs) fluoxetine and sertraline among the first and second-line antidepressants was in keeping with the findings of previous studies (Shireman et al., 2002). During our study period, in 2003, the Committee on Safety of Medicines (CSM) advised against the use of paroxetine in depressed children and adolescents due to an association with increased suicidal ideation (Duff, 2003). Paroxetine was not prescribed to any of our study participants. A similar warning was subsequently issued in late 2004 by the Medicines and Healthcare products Regulatory Agency (MHRA) regarding all SSRIs except fluoxetine, although the SSRIs' association with suicide was not statistically significant (Weller et al., 2004). A 2004 meta-analysis of published and unpublished data for SSRI use in children highlighted fluoxetine as the only SSRI with a consistently favourable risk-benefit profile (Whittington et al., 2004).

Rates of off-label antipsychotic prescribing were significantly lower than might be expected from 
the previous, admittedly sparse, literature. Of a total of 160 antipsychotic prescriptions, 81 (50.6\%) were off-label. This is explained by the diagnosis of a psychotic illness in the vast majority of cases in which antipsychotics were prescribed in our study, thereby allowing almost half of prescriptions to fall within the marketing authorisations of the prescribed medication. In their study of off-label prescribing of psychotropic medications in an adolescent medium secure unit, Haw and Stubbs (Haw and Stubbs, 2010) found 59 of $68(86.8 \%)$ antipsychotic prescriptions to be off-label. The more common diagnoses among this group however included mild intellectual disability, autistic spectrum disorders and complex post-traumatic stress disorder, with schizophrenia and affective psychoses much less common. Medication was most frequently prescribed off-label in this group for behavioural indications and the management of aggression.

Despite the lower than anticipated rate of off-label prescribing observed in our study, it remained high, encompassing more than half of all antipsychotic prescriptions. Even among the first-line antipsychotics, at which point in the prescribing process there would have been several licensed options that had not been tried previously, 47 of 87 prescriptions (54.0\%) were off-label. Almost three-quarters of all off-label antipsychotic prescriptions in our study were for medications (mainly the second-generation antipsychotics olanzapine and quetiapine) not licensed for use at all among under-18s. We note that the National Institute for Health and Care Excellence's (NICE) Technology Appraisal Guidance 43 on second-generation antipsychotics (National Institute for Health and Care Excellence, 2002a) and the organisation's first Clinical Guidelines document on schizophrenia (National Institute for Health and Care Excellence, 2002b) were both published toward the beginning of our study period. Although neither document provided specific advice regarding the use of antipsychotics in under-18s, both provided formalised guidance regarding the preferential use of second-generation antipsychotics (specifically amisulpride, olanzapine, quetiapine, risperidone and zotepine) as first-line treatments of psychotic illnesses due to a reduced incidence of adverse side effects compared to first-generation antipsychotics. It would not be unreasonable to expect that 
this advice had an impact on prescribing patterns among child and adolescent psychiatrists.

Our study has several weaknesses. Although it was reasonably sized, recruitment relied on clinician recall and cooperation, and there exists a possibility that there may have been cases missed during the five-year study period. We are confident for several reasons however that there will have been few such missed cases. Psychotic symptoms of sufficient severity to warrant referrals to CAMHS are relatively rare and therefore memorable, and as such any presentation is likely to have prompted registration with our study. Extensive efforts were made to regularly visit the various CAMHS centres both before and during the study period to ensure comprehensive and thorough recruitment of eligible patients.

We were unable to ascertain which psychotropic medications subjects had been exposed to prior to our study. This information would have been of value when considering the prescription of the lesscommonly used antipsychotic medications, such as the apparent unusually early use of zuclopenthixol discussed above.

The lack of prescription of any psychotropic medication in 8 of the 113 persons $(7.1 \%)$ would suggest that they were not ultimately deemed to be suffering from a psychotic illness; though they were initially thought to be presenting with psychotic symptoms. It is also possible that some patients may simply have been unwilling to accept medications. Had we had diagnoses available for the full dataset this could have been further explored.

Our study did not track the duration of prescription of each antipsychotic, or reasons for switching or discontinuation. Such data would have been useful for comparison with the CAFEPS follow up paper (Noguera et al., 2013), which demonstrated high antipsychotic discontinuation rates of 44.5\% at six months, $59.1 \%$ at 12 months, and $70.9 \%$ at 24 months. 
It is possible that prescribing patterns have changed in the time period since the completion of our analysis due to the withdrawal from use of agents such as zotepine and the emergence of new preparations (paliperidone, asenapine). Anecdotal evidence would point to the growth in the use of quetiapine and aripiprazole among children and adolescents during this time period, the latter of which is licensed for use in the over-15s. It is clear that little research into the use of psychotropics in children and adolescents has been carried out to date and we agree with previous authors who have called urgently for further research into the use of psychotropic medication in this age group (Olfson et al., 2006; Verdoux et al., 2010).

\section{Acknowledgement}

The study was agreed and funded by the Northern Ireland Regional Multiprofessional Audit Group.

\section{Conflict of Interest}

GW has accepted travel and accommodation to UK educational meetings organised by Bristol Myers Squib, Lilly and Janssen during the past three years. 


\section{References}

Aparasu, RR, Bhatara, V (2005) Antipsychotic prescribing trends among youths, 19972002.PsychiatrServ 56: 904.

Aparasu, RR, Bhatara, V (2007) Patterns and determinants of antipsychotic prescribing in children and adolescents, 2003-2004. Current Medical Research and Opinion 23: 49-56.

Baldwin, D, Kosky, N (2007) Off-label prescribing in psychiatric practice. Adv Psychiatric Treat 13: 414-22.

Barrett, SL, Mulholland, CC, Cooper, SJ, Rushe, TM (2009) Patterns of neurocognitive impairment in first-episode bipolar disorder and schizophrenia. Br J Psychiatry 195: 67-72.

Castro-Fornieles, J, Parellada, M, Soutullo, CA, Baeza, I, Gonzalez-Pinto, A, Graell, M, Paya, B, Moreno, D, de la Serna, E, Arango, C (2008) Antipsychotic treatment in child and adolescent firstepisode psychosis: a longitudinal naturalistic approach. Journal of Child and Adolescent Psychopharmacology 18: 327-36.

Cooper, WO, Hickson, GB, Fuchs, C, Arbogast, PG, Ray, WA (2004) New users of antipsychotic medications among children enrolled in TennCare. Arch PediatrAdolesc Med 158: 753-9.

Cooper, WO, Arbogast, PG, Ding, H, Hickson, GB, Fuchs, DC, Ray, WA (2006) Trends in prescribing of antipsychotic medication for US children. AmbulPediatr 6: 79-83.

Doerry, UA, Kent, L (2003) Prescribing practices of community child and adolescent psychiatrists. 
Psychiatr Bull 27: 407-10.

Duff, G (2003) Safety of seroxat (paroxetine) in children and adolescents under 18 yearscontraindication in the treatment of depressive illness. http://www.mhra.gov.uk/home/groups/plp/documents/websiteresources/con019507.pdf (accessed April 22, 2012).

Hafner, H, Maurer, K, Loffler, W, Fatkenheuer, B, An Der Heiden, W, Riecher-Rossler, A, Behrens, S and Gattaz, WF. (1994) The epidemiology of early schizophrenia. Influence of age and gender on onset and early course. Br J Psychiatry Suppl 23: 29-38.

Harrison, JL, Cluxton-Keller, F, Gross, D (2012) Antipsychotic medication prescribing trends in children and adolescents. J Pediatr Health Care 26: 139-45.

Haw, C, Stubbs, J (2010) Off-label psychotropic prescribing for young persons in medium security. Journal of Psychopharmacology 24: 1491-8.

IBM Corp. (2010). IBM SPSS Statistics for Macintosh, Version 19.0. Armonk, NY: IBM Corp.

National Institute for Health and Care Excellence (2002a) Guidance on the use of newer (atypical) antipsychotic drugs for the treatment of schizophrenia. TA43. London: National Institute for Health and Care Excellence.

National Institute for Health and Care Excellence (2002b) Schizophrenia: core interventions in the treatment and management of schizophrenia in primary and secondary care. CG1. London: National Institute for Health and Care Excellence. 
Noguera, A, Ballesta, P, Baeza, I, Arango, C, de la Serna, E, Gonzalez-Pinto, A, Parellada, M, Graell, M, Moreno, C, Otero, S, Castro-Fornieles, J (2013) Twenty-four months of antipsychotic treatment in children and adolescents with first psychotic episode: Discontinuation and tolerability. J ClinPsychopharmacol 33(4): 463-71.

Olfson, M, Blanco, C, Liu, L, Moreno, C, Laje, G (2006) National trends in the outpatient treatment of children and adolescents with antipsychotic drugs. Arch Gen Psychiatry 63: 679-85.

Otasowie, J, Duffy, R, Freeman, J, Hollis, C (2010) Antipsychotic prescribing practice among child psychiatrists and community paediatricians. The Psychiatrist 34: 126-9.

Paediatric Formulary Committee (2007) British national formulary for children 2007. London: British Medical Association, the Royal Pharmaceutical Society of Great Britain, the Royal College of Paediatrics and Child Health, and the Neonatal and Paediatric Pharmacists Group.

Pappadopulos, E, Jensen, PS, Schur, SB, MacIntyre, JC, Ketner, S, Van Orden, K (2002) 'Real world' atypical antipsychotic prescribing practices in public child and adolescent inpatient settings. Schizophr Bull 28: 111-21.

Pogge, DL, Singer, MB, Harvey, PD (2005) Rates and predictors of adherence with atypical antipsychotic medication: a follow-up study of adolescent inpatients. J Child AdolescPsychopharmacol 15: 901-12.

Rani, F, Murray, ML, Byrne, PJ, Wong, ICK (2008) Epidemiologic features of antipsychotic prescribing to children and adolescents in primary care in the United Kingdom. Pediatrics 121: 1002-9. 
Shireman, TI, Olson, BM, Dewan, NA(2002) Patterns of antidepressant use among children and adolescents. Psychiatric Services 53: 1444-50.

Sivaprasad, L, Hassan, T, Handy, S (2006) Survey of atypical antipsychotic use by child and adolescent psychiatrists. Child Adolesc Mental Health 11: 164-7.

Stigler, KA, Potenza, MN, Posey, DJ, McDougle, CJ (2004) Weight gain associated with atypical antipsychotic use in children and adolescents: prevalence, clinical relevance and management. Paediatric Drugs 6: 33-44.

Thomas, CR, Holzer, CE (2006) The continuing shortage of child and adolescent psychiatrists. J Am Acad Child Adolesc Psychiatry 45: 1023-31.

Turkington, A, Mulholland, CC, Rushe, TM, Anderson, R, McCaul, R, Barrett, SL, Barr, RS and Cooper, SJ. (2009) Impact of persistent substance misuse on 1-year outcome in first-episode psychosis. Br J Psychiatry 195: 242-48.

Verdoux, H, Tournier, M, Begaud, B (2010) Antipsychotic prescribing trends: a review of pharmaco-epidemiological studies. ActaPsychiatrScand 121: 4-10.

Weller, IVD, Ashby, D, Brook, R, Chambers, MGA, Chick, JD, Drummond, C, Ebmeier, KP, Gunnell, DJ, Hawking, H, Mukaetova-Ladinska, E, O’Tierney, E, Taylor, RJ, York, A, and Zwi, M. (2004) Report of the CSM expert working group in the safety of selective serotonin reuptake inhibitor antidepressants. http://www.mhra.gov.uk/home/groups/plp/documents/drugsafetymessage/con019472.pdf (Accessed 22 April, 2012). 
Whittington, CJ, Kendall, T, Fonaghy, P, Cottrell, D, Cotgrove, A, Boddington, E (2004) Selective serotonin reuptake inhibitors in childhood depression: systematic review of published versus unpublished data. Lancet 363: 1341-5. 
Table 1 Frequency of psychotropic medication prescribing

\begin{tabular}{|c|c|c|}
\hline Medication Prescribed & Frequency & Percentage \\
\hline Yes & 100 & 88.5 \\
\hline No & 8 & 7.1 \\
\hline \multirow[t]{2}{*}{ Unknown $^{\mathrm{a}}$} & 5 & 4.4 \\
\hline & 113 & 100 \\
\hline
\end{tabular}

'Retrospective analysis of all 113 patients' clinical case notes was not possible due to the destruction of five volumes of notes in a fire.

Table 2 Breakdown of first new psychotropic prescriptions by class

\begin{tabular}{|c|c|c|}
\hline First New Medication (Class) & Frequency & Percentage \\
\hline Antipsychotic & 65 & 65 \\
\hline Antidepressant & 14 & 14 \\
\hline Antipsychotic and antidepressant & 13 & 13 \\
\hline Benzodiazepine & 4 & 4 \\
\hline Stimulant & 1 & 1 \\
\hline \multirow[t]{2}{*}{ Unknown $^{\mathrm{a}}$} & 3 & 3 \\
\hline & 100 & 100 \\
\hline
\end{tabular}

alt was impossible to determine the first class of medication prescribed in three patients due to the destruction of the clinical notes.

Table 3 Patterns of antipsychotic (AP) prescribing, from first to fourth-line agents

\begin{tabular}{|c|c|c|c|c|c|c|c|c|}
\hline Antipsychotic (AP) & $\begin{array}{l}\text { First AP } \\
\text { Frequency }\end{array}$ & $\begin{array}{l}\text { First AP } \\
\text { Percentage }\end{array}$ & $\begin{array}{l}\text { Second AP } \\
\text { Frequency }\end{array}$ & $\begin{array}{l}\text { Second AP } \\
\text { Percentage }\end{array}$ & $\begin{array}{l}\text { Third AP } \\
\text { Frequency }\end{array}$ & $\begin{array}{l}\text { Third AP } \\
\text { Percentage }\end{array}$ & $\begin{array}{l}\text { Fourth AP } \\
\text { Frequency }\end{array}$ & $\begin{array}{l}\text { Fourth AP } \\
\text { Percentage }\end{array}$ \\
\hline Amisulpride & 2 & 2.1 & 5 & 11.4 & 2 & 10 & & \\
\hline Aripiprazole & & & 2 & 4.5 & 3 & 15 & & \\
\hline Chlorpromazine & 12 & 12.5 & 7 & 15.9 & 1 & 5 & 2 & 22.2 \\
\hline Clozapine & & & 4 & 9.1 & 4 & 20 & 1 & 11.1 \\
\hline FlupentixolDecanoate & & & 1 & 2.3 & 1 & 5 & & \\
\hline FluphenazineDecanoate & & & & & 1 & 5 & & \\
\hline Haloperidol & 1 & 1 & 2 & 4.5 & 2 & 10 & & \\
\hline Olanzapine & 23 & 24 & 7 & 15.9 & 4 & 20 & 1 & 11.1 \\
\hline Quetiapine & 4 & 4.2 & 4 & 9.1 & 1 & 5 & & \\
\hline Risperidone & 44 & 45.8 & 9 & 20.5 & 1 & 5 & 3 & 33.3 \\
\hline Sulpiride & & & 2 & 4.5 & & & & \\
\hline Zotepine & & & 1 & 2.3 & & & 1 & 11.1 \\
\hline Zuclopenthixol & 1 & 1 & & & & & 1 & 11.1 \\
\hline Unknown $^{a}$ & 9 & 9.4 & & & & & & \\
\hline Total & 96 & 100 & 44 & 100 & 20 & 100 & 9 & 100 \\
\hline
\end{tabular}

AP, antipsychotic

alt was impossible to determine the first AP prescribed in nine cases, due to either the destruction of clinical notes or the quality of the clinical records. 
Table 4 Patterns of antidepressant (AD) prescribing, from first to third-line agents

\begin{tabular}{|c|c|c|c|c|c|c|}
\hline $\begin{array}{l}\text { First } \\
\text { Antidepressant } \\
\text { (AD) }\end{array}$ & $\begin{array}{l}\text { First } \\
\text { Antidepressant } \\
\text { Frequency }\end{array}$ & $\begin{array}{l}\text { First } \\
\text { Antidepressant } \\
\text { Percentage }\end{array}$ & $\begin{array}{l}\text { Second } \\
\text { Antidepressant } \\
\text { Frequency }\end{array}$ & $\begin{array}{l}\text { Second } \\
\text { Antidepressant } \\
\text { Percentage }\end{array}$ & $\begin{array}{l}\text { Third } \\
\text { Antidepressant } \\
\text { Frequency }\end{array}$ & $\begin{array}{l}\text { Third } \\
\text { Antidepressant } \\
\text { Percentage }\end{array}$ \\
\hline Citalopram & 4 & 9.3 & & & & \\
\hline Clomipramine & & & 1 & 7.7 & & \\
\hline Dosulepin & & & 1 & 7.7 & 1 & 16.7 \\
\hline Escitalopram & 2 & 4.7 & & & & \\
\hline Fluoxetine & 21 & 48.8 & 2 & 15.4 & & \\
\hline Lofepramine & & & & & 1 & 16.7 \\
\hline Mirtazapine & 4 & 9.3 & 2 & 15.4 & 1 & 16.7 \\
\hline Sertraline & 10 & 23.3 & 6 & 46.2 & 1 & 16.7 \\
\hline Venlafaxine & 2 & 4.7 & 1 & 7.7 & 2 & 16.7 \\
\hline Total & 43 & 100 & 13 & 100 & 6 & 100 \\
\hline
\end{tabular}

Table 5 Patterns of prescribing of first 'other' medications

\begin{tabular}{|l|l|l|}
\hline First Other Medication & Frequency & Percentage \\
\hline Atomoxetine & 3 & 12 \\
\hline Buspirone & 3 & 12 \\
\hline Lithium & 5 & 25 \\
\hline Melatonin & 2 & 8 \\
\hline Procyclidine & 5 & 25 \\
\hline Zolpidem & 3 & 12 \\
\hline Zopiclone & 4 & 16 \\
\hline & 25 & 100 \\
\hline
\end{tabular}

Table 6 Levels of off-label antipsychotic prescribing, from first to fourth-line agents

\begin{tabular}{|l|l|}
\hline Medication & Percentage of prescriptions off-label \\
\hline First Antipsychotic & 54 \\
\hline Second Antipsychotic & 40.9 \\
\hline Third Antipsychotic & 55 \\
\hline Fourth Antipsychotic & 55.6 \\
\hline
\end{tabular}

Table 7 Off-label antipsychotic prescriptions by reason adjudged to be off-label

\begin{tabular}{|l|l|l|}
\hline Reason prescription adjudged to be off-label & Frequency & Percentage \\
\hline Not licensed at all in under-18s & 58 & 71.6 \\
\hline Prescribed outside licensed age range & 19 & 23.5 \\
\hline Prescribed outside licensed indication(s) & 4 & 4.9 \\
\hline Prescribed outside licensed dose range & 0 & 0 \\
\hline & 81 & 100 \\
\hline
\end{tabular}

